\title{
Development of solar panel cleaning robot using arduino
}

\author{
Faridah Hanim Mohd Noh ${ }^{1}$, Muhamad Faizal Yaakub ${ }^{2}$, Ili Najaa Aimi Mohd Nordin ${ }^{3}$, Norain Sahari ${ }^{4}$, \\ Nor Aira Zambri ${ }^{5}$,Sim Sy Yi ${ }^{6}$, Muhammad Syukri Mohd Saibon ${ }^{7}$ \\ ${ }^{1,3,4,5,6}$ Faculty of Engineering Technology, Universiti Tun Hussein Onn Malaysia, Malaysia \\ ${ }^{2}$ Faculty of Electrical and Electronics Engineering Technology, Universiti Teknikal Malaysia Melaka, Malaysia \\ ${ }^{7}$ Faculty of Electrical \& Electronic Engineering, Universiti Tun Hussein Onn Malaysia, Malaysia
}

\begin{tabular}{l} 
Article Info \\
\hline Article history: \\
Received Feb 22, 2020 \\
Revised Apr 7, 2020 \\
Accepted Apr 17, 2020 \\
\hline
\end{tabular}

Keywords:

Arduino controller system Automatic solar panel cleaning system

Photovoltaic panels

\begin{abstract}
Solar power is mainly harnessed from photovoltaic (PV) panels which are arranged in multiple arrays in a solar farm or solar system. Though, power generation from PV solar system is characterised by uncertain efficiency, many countries with high insolation prefer solar as an alternative way of generating clean energy. However, the efficiency of energy generated from PV panels is affected by the accumulation of dust and debris, even on one panel in an array. This condition leads to the need for regular cleaning of the surface of PV panels. Current labour-based cleaning methods for photovoltaic arrays are costly in time, water and energy usage as well as lacking in automation capabilities. To overcome this problem, a fully automatic solar panel cleaning system with/without water is proposed. Hence, in this paper, the design of a robot for automated cleaning of the surface of PV panel is presented. The design utilizes an Arduino controller system to control the robot movement during the cleaning process. In addition, it is equipped with two rough sponge and a water pump system that can be used to clean dust or debris found on PV panel surfaces. The efficiency of the PV panels before and after the cleaning process is also observed. The result shows that the developed solar panel cleaning robot is able to clean the panel effectively and increase back the output current as well as the maximum power of the panel by $50 \%$, after the dust on the PV panel is cleaned.
\end{abstract}

Copyright $(0) 2020$ Institute of Advanced Engineering and Science. All rights reserved.

\section{Corresponding Author:}

Faridah Hanim Binti Mohd Noh,

Department of Electrical Engineering Technology,

Faculty of Engineering Technology,

Universiti Tun Hussein Onn Malaysia,

86400 Parit Raja, Johor, Malaysia.

Email: hanim@uthm.edu.my

\section{INTRODUCTION}

This new century is marked by growth in the usage of PV, both in research and market proliferation. Renewable energies, especially photovoltaics (PV) are regarded as an important contribution for decarbonisation of our energy system. In October; 2019, Bloomberg New Energy Finance found that the prices of wind and solar power continue to fall. The commerce offers to supply PV-generated electricity by $11 \%$ cheaper compared to in 2018, which reduces solar power prices compared to coal and gas power plants. This is attributed primarily to incentive programs such as the feed-in tariffs in Germany and Europe, and system buydown subsidies in Japan and the US. With China's dominance of manufacturing (and accompanying beneficial collapse in PV prices) starting in 2009/2010 - as well as the rise in interest in new markets and investments in the desert locations (Saudi Arabia, Qatar, U.A.E. and other Gulf countries, Egypt, India, as well as the US, Australia, and China), leads to the continous growth of solar energy in generation and installation worldwide 
until this recent year [1-3]. However, areas with high levels of irradiation (the Sun-Belt region) often suffer from high dust and limited water resources. The deposition of dust and dirt on a PV module or mirror surface leads to power loss as it reduces the solar energy received by the collector by absorbing or dispersing the sunlight. Other than that, the efficiency of solar panels decreases with time, added by other factors such as fallen leaves and patches of water. Therefore, many efforts have been made to optimise cleaning strategies, including wet or dry cleaning methods, automatic or manual cleaning methods, different types of brushes or fabrics, or chemical additives. Besides the cleaning mechanism, another dust mitigation strategy is to use natural cleaning mechanisms such as wind and rain. In areas with low rainfall and high humidity, such as dry and semi-arid climates, dust removal by wind can be used as a natural cleansing mechanism. Apart from cleaning methods, many studies have been taken to develop anti-soiling coating [4-10].

Automatic self-cleaning has been adapted to overcome the difficulties that arise from traditional cleaning or manual method and to avoid a lack of productivity due to the deposition of dust [11]. As mentioned earlier, there are several factors affecting PV energy efficiencies, such as bird droppings, sea salt, shadows, pollen, dust, snow, high temperatures, and dirt. However, the main factor affecting the efficiency of the PV panel is dust, which can reduce its efficiency by up to $50 \%$, depending on the surrounding environment. Numerous works have been conducted around the globe for solar panel automatic self-cleaning. For instance, [12] has introduced a 'solar panel cleaning robot' that clean PV array. With a dimension range between 1 to 16 meters, the $12 \mathrm{~V}$ powered robot cleans the PV panel arrays by moving its vertically installed cleaning brush in the horizontal axis. At the same time, water from an attached hose is supplied to wet a panel automatically during cleaning. This feature is fully autonomous with double stage programme functioning through a water jet and a rain sensor. Two ways communication and control from remote sites are possible with the installation of text massaging system between users and the robot. In 2013, Sabot Swiss Innovation has introduced a mobile cleaning robot mechanism known as 'Gekko Solar' to solar PV panels with a cleaning capacity up to $400 \mathrm{~m}^{2}$. The robot is controlled remotely by an operator using a joystick panel and the cleaning process is through a rotating brush. It features a flexible movement in every direction with trapezoid-shapes geared belt drives with vacuum technology. The same company also came up with another version of Gekko robot known as 'Gekko Solar Farm' to cater to the wider cleaning capacity up to $2000 \mathrm{~m}^{2}$ per hour. The mechanism is supported by a crane arm with a $30^{\circ}$ incline capability and able to transverse up to $60 \mathrm{~cm}$ gap $[13,14]$.

Later in 2015, [15] claimed that by adding an automated cleaning device that senses the dirt on the PV panels is a way to easily clean the dirt. The proposed mechanism uses the 8051 series microcontroller to control the DC geared motor and other input/output processes. The mechanism consists of LDR sensors for dirt detection and sliding brushes to clean the PV panels. Analysis of the dust composition revealed unique pollutants like ash, sand, silica, calcium carbonate, and crimson soil. The power output can be expanded by approximately $30 \%$ by using a computerised cleaning scheme.

Studies done by [16] found that Libya often carries dust and sand from February to May. The small particles from the sand and dust accumulate on the PV panel surface and block the sunlight from reaching the modules. Due to this problem, a solution to clean the energy resources in the desert region is proposed. The experimental set up on weekly cleaning on PV panel throughout the period and simultaneous measuring is implemented in maximum operating voltage and currents on each module before and after washing modules. Weekly water washing is carried out through periods of February to May in order to evaluate the performance of PV panels. So, the maximum current and voltage is measured at the terminal using the digital multi-meter device, before and after washing in order to gain the maximum power at the operating point generated by PV module.

Sims et al. [17] and Bock et al. [18] designed an electro-dynamic based self-cleaning PV module. Their designs show that the rate of dust elimination increased with the value of voltage. However, this type of cleaning method has some disadvantages such as it cannot eliminate the muddy or adhesive particles because it does not contain any liquid and its initial and operating cost is quite expensive. Mani et. al [19] discussed the impact of dust settlement on the operation of the PV module during two phases, 1940 - 1990 and 1990 - 2010. A focal point of this examination is about the effect of ecological factors on the operation of PV module without finding the effective techniques of reducing their impact. Mekhilef et al. [20] studied the effects of dust settlement, wind speed, and humidity on the PV module. They reported that each factor influences the other and that they should be measured simultaneously. Jamil et al. [21] reviewed the types of soiling and discussed the comparison of present mitigation methods of soiling. Syed et al. [22] revised the impact of the ecological condition and dirt settlement on the output of the PV module. They concluded that the most effective dust elimination process depends on the weather circumstances at the site of installation. There is no permanent recommended rate of PV module cleaning as this mainly depends on the occurrence of dust storms. The studies done by Costa et al. [23], Darwish et al. [24], Sayyah et al. [25], and Sarver et al. [26], provide information related to soiling effect on the performance of the PV system in different areas and countries. 
This research aims to construct a solar panel cleaning robot using Arduino. The objectives of the project are to design and implement a microcontroller-based dust cleaning system by using Arduino UNO as the main system, to optimise the performance of PV panel operation under dusty environment, and to improve the efficiency of the solar panel by keeping them clean.

\section{SYSTEM DESIGN AND DEVELOPMENT}

\subsection{System overview}

Figure 1 shows the block diagram of the proposed solar panel cleaning robot. It comprises a microcontroller unit, battery, ultrasonic sensor, two-wheel-drive (WD) car chassis with DC motor, water pump, water tank, and brushes. The major heart of this project is the microcontroller unit. The microcontroller unit controls the movement of the DC motor based on the input given by the ultrasonic sensor. It also determines the time to pump water to the brushes during the cleaning process. In this system, an ultrasonic sensor detects the movement distance of the proposed robot. The built-in cleaning device in the robot consists of static brushes, placed at the front and the backside of the robot, a water pump, and a water tank. Water is supplied to the brushes from the water tanks via a dedicated water pump, whose function is to pump the water at a suitable pressure. The list of hardware used in the development of the proposed prototype is given in Table 1 .

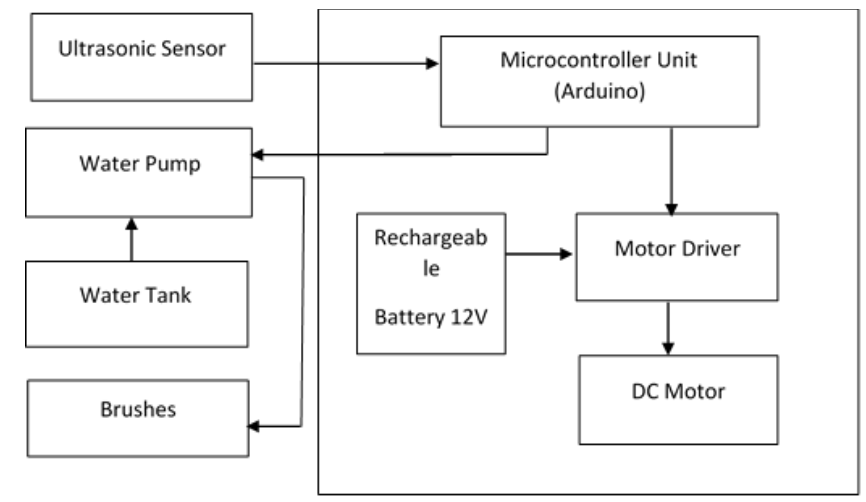

Figure 1. Block diagram for the designed solar panel cleaning robot

Table 1. List of hardware

\begin{tabular}{ccc}
\hline No. & Component & Description \\
\hline 1 & Arduino UNO R3 & Motor Driver L293D \\
2 & 2WD chassis car with 2DC & $\begin{array}{r}\text { To control the overall cleaning process of the robot } \\
\text { Embedded with Arduino UNO to connect the DC motor }\end{array}$ \\
3 & The body of the robot, holds the ultrasonic sensor, rechargeable battery, \\
microcontroller unit, and brushes.
\end{tabular}

\subsection{Complete hardware}

The complete setup of this solar panel cleaning robot is shown in Figure 2 and Figure 3. When the switch is on, the robot moves forward with a speed of $100 \mathrm{rpm}$. The ultrasonic sensor is also turned on and starts to read the movement distance of the robot. If the movement distance of the robot is less than 5 $\mathrm{cm}$, the robot continues to move forward. When the movement distance of the robot is farther than $5 \mathrm{~cm}$, then the robot starts to move backward. The robot stops moving backward after the time delay set in the microcontroller reaches $1000 \mathrm{~ms}$. Then it moves forward in a straight line again. This process is repeated until the robot is turned off. Since this robot was tested on a small solar panel, it was coded to move in a straight line, forward and backward. If the system is tested on a bigger array of solar panels, the robot movement can be coded as per proper walking path so that it can clean all the solar panels efficiently. 


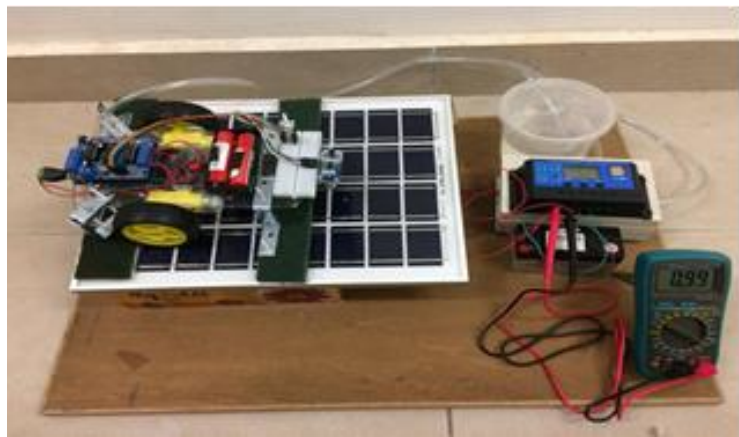

Figure 2. The complete setup of solar panel cleaning robot

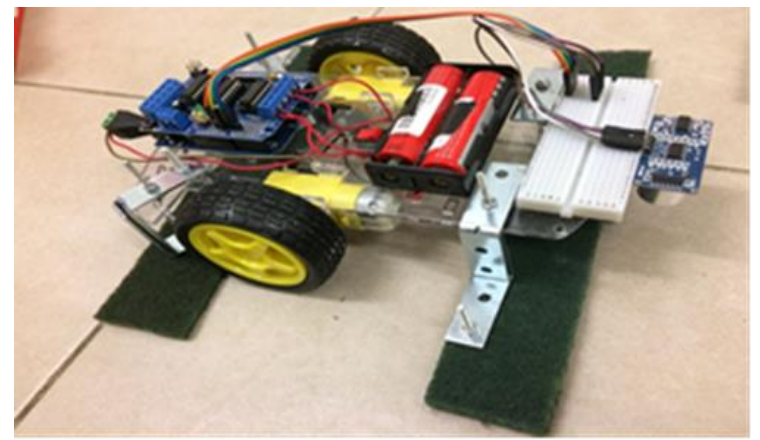

Figure 3. The complete robot prototype

\subsection{Solar panel characteristics}

To test the effectiveness of the developed solar panel cleaning robot, several experiments on cleaning a dusty solar panel were conducted. In these experiments, flour was used to imitate dust on a solar panel. The tests were done by measuring voltage and current of the tested solar panel at initial condition (without dust), at dusty condition, and after the dust cleaning process. Figure 4 illustrates the condition applied to the solar panel for the experimental setup.

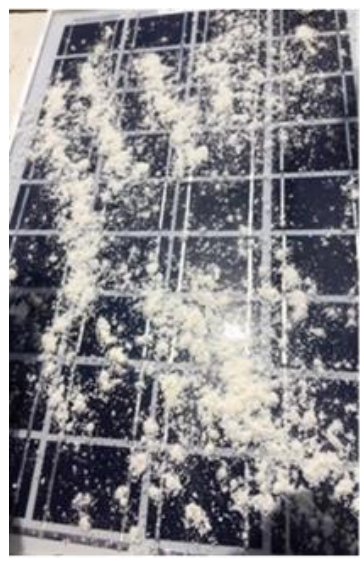

(a)

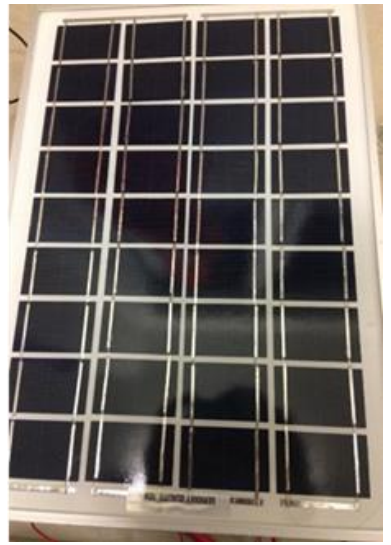

(b)

Figure 4. Experimental setup, (a) When the solar panel is covered with dust (using flour),

(b) When the solar panel is cleaned using the developed robot

For the experimental procedure, the current and voltage of undusted, dusty and cleaned solar panel were measured every one hour, start from $11.00 \mathrm{a} . \mathrm{m}$. until $2.00 \mathrm{p} . \mathrm{m}$. Then the real power of the solar panel was calculated using the following equation:

$$
P=V \times I
$$

\section{RESULTS AND ANALYSIS}

The measured data is tabulated in Table 2. The calculated real power obtained from the measured voltage and current is provided in Table 3. Figure 5 provides the current versus voltage (I-V) characteristic of the undusted, dusty and cleaned solar panel. From the data given in Table 2, the current decreased by almost $50 \%$ when the solar panel was covered by dust. The real power provided by the solar panel also decreased linearly with the reduction of the current. Then the cleaning process was done by using the developed robot. After the dust cleaning process, the current increased back almost by $50 \%$. These conditions can be seen from the data provided in Table 2 and Table 3. 
Table 2. Measured voltage and current of tested solar panel

\begin{tabular}{ccccccc}
\hline \multirow{2}{*}{ Time } & \multicolumn{2}{c}{ Before Dust } & \multicolumn{2}{c}{ During Dust } & \multicolumn{2}{c}{ After Cleaning } \\
& $\mathrm{V}(\mathrm{v})$ & $\mathrm{I}(\mathrm{mA})$ & $\mathrm{V}(\mathrm{v})$ & $\mathrm{I}(\mathrm{mA})$ & $\mathrm{V}(\mathrm{v})$ & $\mathrm{I}(\mathrm{mA})$ \\
\hline $11.00 \mathrm{am}$ & 19.07 & 136.23 & 19.07 & 54.31 & 19.07 & 134.3 \\
$12.00 \mathrm{pm}$ & 19.22 & 142.70 & 19.22 & 56.39 & 19.22 & 145 \\
$13.00 \mathrm{pm}$ & 19.31 & 140.53 & 19.31 & 56.91 & 19.31 & 141.6 \\
$14.00 \mathrm{pm}$ & 19.28 & 132.95 & 19.28 & 53.92 & 19.28 & 131.9 \\
\hline
\end{tabular}

Table 3. Calculated real power of tested solar panel

\begin{tabular}{cccc}
\hline \multirow{2}{*}{ Time } & Before Dust & $\begin{array}{c}\mathrm{P}(\mathrm{W}) \\
\text { During Dust }\end{array}$ & After Cleaning \\
\hline $11.00 \mathrm{am}$ & 2597.85 & 1035.65 & 2561.10 \\
$12.00 \mathrm{pm}$ & 2742.76 & 1083.89 & 2786.90 \\
$13.00 \mathrm{pm}$ & 2713.62 & 1098.90 & 2734.30 \\
$14.00 \mathrm{pm}$ & 2756.00 & 1039.60 & 2543.03 \\
\hline
\end{tabular}

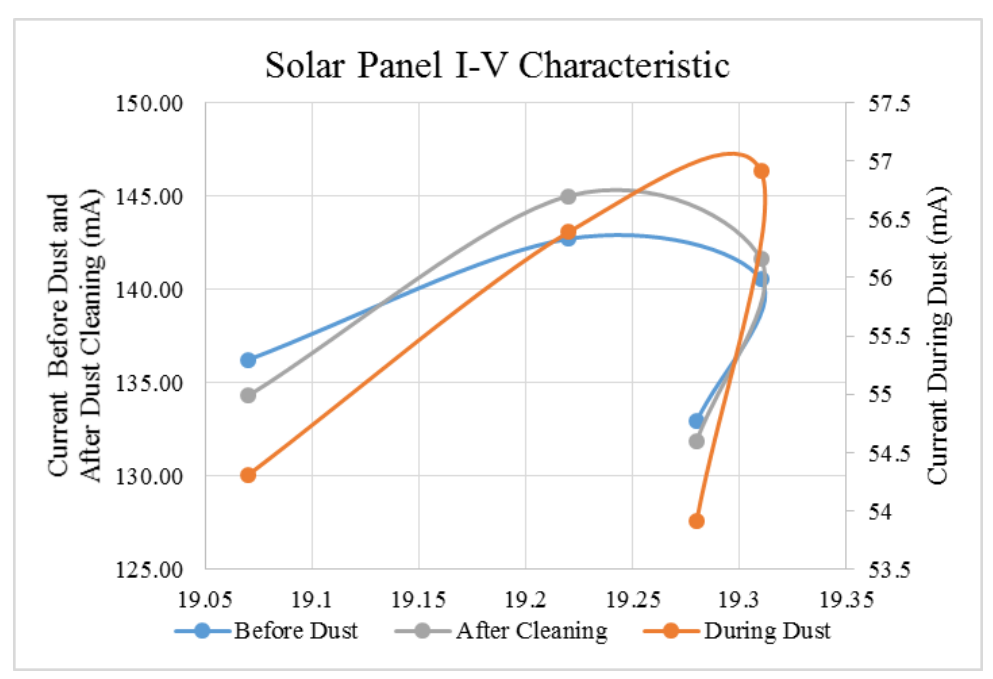

Figure 5. Solar panel I-V characteristic

\section{CONCLUSION}

In this paper, a fully assembled solar panel cleaning robot has been developed. The control algorithm and cleaning sequence are established with the Arduino platform. The robot is designed to be fully powered by rechargeable batteries. The experiment and verification results demonstrated the functionality of the cleaning robot to performed its duty. The solar photovoltaic output power is successfully restored to its maximum power capacity after the cleaning process, even though there are slight losses due to some glitch error in the system. The 50\% improvement at the output current as well as the maximum power before and after cleaning reveal that the robot guarantees the effectiveness of the developed robot.

\section{ACKNOWLEDGEMENTS}

The authors would like to acknowledge the financial support received from the Research Management Centre (RMC) Universiti Tun Hussein Onn Malaysia (UTHM) under the Tier 1 Research Grant Scheme (Code H105). The authors would also like to thanks the Power Energy Focus Group, Advanced Technology Centre (ATC), Faculty of Engineering Technology, UTHM and Green and Sustainable Energy, Faculty of Electrical and Electronics Engineering (GSEnergy), UTHM for the resources and support given.

\section{REFERENCES}

[1] A. A. Rahimoon, et al., "Design of parabolic solar dish tracking system using arduino," Indonesian Journal of Electrical Engineering and Computer Science, vol. 17, no. 2, pp. 914-921, 2020.

[2] A. Saleem, et al., "The effect of environmental changes on the efficiency of the PV system," Indonesian Journal of Electrical Engineering and Computer Science, vol. 18, no. 1, pp. 558-564, 2020.

[3] M. F. Yaakub, et al., "Prospective study of power generation from natural resources using hybrid system for remote area," Indonesian Journal of Electrical Engineering and Computer Science, vol. 18, no. 2, pp. 642-647, 2020.

[4] S. R. Hunter, et al., "Low cost anti-soiling coatings for CSP collector mirrors and heliostats," High Low Concentrator Systems for Solar Energy Applications IX, vol. 9175, p. 91750J, 2014.

[5] M. A. Bahattab, et al., "Anti-soiling surfaces for PV applications prepared by sol-gel processing: Comparison of laboratory testing and outdoor exposure," Solar Energy Materials and Solar Cells, vol. 157, pp. 422-428, 2016.

[6] Y. Y. Quan and L. Z. Zhang, "Experimental investigation of the anti-dust effect of transparent hydrophobic coatings applied for solar cell covering glass," Solar Energy Materials and Solar Cells, vol. 160, pp. 382-389, 2017.

[7] M. Sakhuja, et al., "Outdoor performance and durability testing of antireflecting and self-cleaning glass for photovoltaic applications,” Solar Energy, vol. 110, pp. 231-238, 2014. 
[8] Q. F. Xu, et al., "An Anti-Reflective and Anti-Soiling Coating for Photovoltaic Panels College of Staten Island and Graduate Center of the City University of New York," in Advanced Materials: TechConnect Briffs 2015, pp. 624-627, 2015.

[9] K. Midtdal and B. P. Jelle, "Self-cleaning glazing products: A state-of-the-art review and future research pathways," Solar Energy Materials and Solar Cells, vol. 109, pp. 126-141, 2013.

[10] L. Yao and J. He, "Recent progress in antireflection and self-cleaning technology - From surface engineering to functional surfaces," Progress in Materials Science, vol. 61, pp. 94-143, 2014.

[11] G. Webster, "Spirit Gets Energy Boost from Cleaner Solar Panels," Jet Propulsion Laboratory, Pasadena, Calif., 2009. Available: https://www.nasa.gov/mission_pages/mer/news/mer-20090212.html.

[12] Washpanel s.r.l., "Portable system device/reference for solar field/flat roof/shed," 2013. Available: http://www.washpanel.com/en/documenti.php.

[13] Serbot AG, "TD_GEKKO Solar." Available: http://serbot.ch/images/documents/TD_GEKKO Solar_En_2013_06_06.pdf.

[14] Serbot AG, "GEKKO Solar Farm Roboter." Available: http://serbot.ch/images/documents/TD_GEKKO SolarFarm_En_2013_06_26.pdf.

[15] S. B. Halbhavi, et al., "Microcontroller Based Automatic Cleaning of Solar Panel," International Journal of Latest Trends in Engineering and Technology, vol. 5, no. 4, pp. 99-103, 2015.

[16] A. O. Mohamed and A. Hasan, "Effect of Dust Accumulation on Performance of Photovoltaic Solar Modules in Sahara Environment," Journal of Basic and Applied Scientific Research, vol. 2, no. 11, pp. 11030-11036, 2012.

[17] R. A. Sims, et al., "Development of a transparent self-cleaning dust shield for solar panels," in Proceedings ESAIEEE joint meeting on electrostatics, 2003.

[18] J. P. Bock, et al., "An efficient power management approach for self-cleaning solar panels with integrated electrodynamic screens," Proceedings of ESA Annual Meeting on Electrostatics Paper O2, 2008.

[19] M. Mani and R. Pillai, "Impact of dust on solar photovoltaic (PV) performance: Research status, challenges and recommendations," Renewable and Sustainable Energy Reviews, vol. 14, no. 9, pp. 3124-3131, 2010.

[20] S. Mekhilef, et al., "Effect of dust, humidity and air velocity on efficiency of photovoltaic cells," Renewable and Sustainable Energy Reviews, vol. 16, no. 5, pp. 2920-2925, 2012.

[21] W. J. Jamil, et al., "Performance degradation of photovoltaic power system: Review on mitigation methods," Renewable and Sustainable Energy Reviews, vol. 67, pp. 876-891, 2017.

[22] S. A. M. Said, et al., "The effect of environmental factors and dust accumulation on photovoltaic modules and dustaccumulation mitigation strategies," Renewable and Sustainable Energy Reviews, vol. 82, no. 1, pp. 743-760, 2018.

[23] S. C. S. Costa, et al., "Dust and soiling issues and impacts relating to solar energy systems: Literature review update for 2012-2015," Renewable and Sustainable Energy Reviews, vol. 63, pp. 33-61, 2016.

[24] Z. A. Darwish, et al., "Effect of dust pollutant type on photovoltaic performance," Renewable and Sustainable Energy Reviews, vol. 41, pp. 735-744, 2015.

[25] A. Sayyah, et al., "Energy yield loss caused by dust deposition on photovoltaic panels," Solar Energy, vol. 107, pp. 576-604, 2014.

[26] T. Sarver, et al., "A comprehensive review of the impact of dust on the use of solar energy: History, investigations, results, literature, and mitigation approaches," Renewable and Sustainable Energy Reviews, vol. 22, pp. 698-733, 2013. 